\title{
For a Left Populism
}

\author{
Chantal Mouffe \\ New York, Estados Unidos, 2018, 98 p.
}

\author{
Claudio Riveros Ferrada \\ Universidad de Talca, Talca, Chile. \\ Email: clriveros@utalca.cl
}

\begin{abstract}
El libro de Chantal Mouffe, For a Left Populism, podría considerarse una reflexión de largo aliento, que se enmarca en el trabajo que inició junto a Laclau en Hegemonía y Estrategia Socialista y que luego la autora extendió con sello propio en Onthe Political (2005) y en The Democratic Paradox (2000). Es por esta razón que el presente libro, no se enfoca -ni se agota- en determinar la naturaleza del populismo, sino que estudia al fenómeno dentro de una perspectiva más amplia, tanto a nivel teórico, pero sobre todo como proyecto político. Se plantea así, que el populismo es una estrategia discursiva que permitirá radicalizar la democracia en tiempos de postpolítica, siendo éste el argumento central que recorre los cuatro capítulos de este breve texto que está escrito en tono de ensayo. Sin duda el hecho que sea un ensayo, hace difícil la presentación secuencial de los capítulos, pues los argumentos se contienen y suceden en torno a bases teóricas sobre las cuales se despliegan sus tesis principales. Por último, habría que destacar que la propuesta de Mouffe tiende a explicar el fenómeno europeo, aunque ello no significa que no se pueda aplicarse a otros continentes y contextos.
\end{abstract}

Es imposible entender la propuesta de Mouffe sin sopesar qué entiende ella por democracia y postpolítica. Respecto a la democracia, habría que señalar, por una parte, que la autora sigue la línea teórica que distingue entre democracia y liberalismo. De hecho, propone que la denominada democracia liberal no es sino un proceso histórico concreto, de la modernidad europea, que permite la convivencia de dos lógicas distintas: una democrática (demos) y otra liberal (politeia). Así, mientras la tradición del liberalismo político propugna el rule of law, la separación de los poderes del Estado y la defensa de la libertad individual, la noción democrática, en cambio, apuntaría a la igualdad y a la soberanía popular (13-14). Por otra, y si bien hay una crítica a la identificación del liberalismo con la democracia, esto no implica que la autora deseche el liberalismo, por cuanto el pluralismo y parte de su institucionalidad son elementos a considerar y consolidar. En este sentido, si bien Mouffe reivindica autores como Carl Schmitt, se separa finalmente de él en tanto no considera que la contradicción inacabable entre ambas tradiciones generará la destrucción de una de ellas. Combate así la reducción de la democracia a su componente liberal, la cual se limitaría al aseguramiento de elecciones libres y a la defensa de los D.D.H.H. (17-18). Por el contrario, propone radicalizar la democracia, lo cual contrario a lo que podría imaginarse, no significa una ruptura total (de tipo revolucionaria o refundacional) con la democracia liberal y la posterior creación de un régimen ex nihilo, apuntando más bien a la conservación de la institucionalidad liberal como la división de los poderes del Estado, el multipartidismo, la representación y los derechos civiles. En efecto, la autora hace un llamado a radicalizar los principios ético-políticos del régimen liberal-democrático mediante el discurso populista. Así, entonces, lo que se busca es que los principios de libertad e igualdad no sean removidos, sino que sean realmente implementados en el marco de una democracia pluralista, donde se conciba a la política como un constante proceso de negociación y tensión agonista entre distintas hegemonías.

Mouffe busca así, la profundización de lo político, lo cual se construye a partir de la oposición de un ellos y un nosotros, no como enemigos, mas sí como adversarios irreconciliables en tanto depositarios de distintos horizontes normativos. En simple, lo que propone la autora, es que lo político debe entenderse como 
un juego de inclusión-exclusión entre distintos grupos que propugnan la diferencia (ellos) pero que a la vez logran su identificación (nosotros), aunque claro está, como dos entidades en continua formación y reproducción que no obedecen a procesos constitutivos previos. Por lo mismo, la clausura de este proceso no se puede si no entender como la muerte de lo político, ya que a fin de cuentas, la construcción de fronteras antagónicas que traducen el conflicto y la división existente en una sociedad, son del todo compatibles -y absolutamente necesarias- con los valores democráticos.

Ahora bien, lo que habría caracterizado a la política de los últimos cuarenta años es la postpolítica, esto es, un período de tiempo en el que el orden hegemónico no es antagonizado y en el que la política se limita al conjunto de prácticas e instituciones a través de las cuales se expresa el orden, la estabilidad; en suma, donde no hay conflictos normativos que expresen las distintas visiones de los distintas clases o grupos presentes en la sociedad. Así, propone la autora, desde el advenimiento del neoliberalismo, que tuvo como figura prominente a Margaret Tatcher, se habría consolidado una visión de mundo de tipo tecnocrática que, entre otras cosas, impone la regla del mercado (desregulación, privatización y austeridad fiscal), limita el rol del Estado a la protección de los derechos privados y termina reduciendo a la sociedad a un individualismo posesivo (11-12). Este fenómeno -indica- no se habría producido sin la complicidad de los partidos social demócratas, quienes habrían renunciado a la disputa de la hegemonía política, convirtiéndose en partidos que reivindicarían el consenso como mecanismo de la buena política.

Sin embargo, advierte Mouffe, la hegemonía neoliberal habría empezado a ser contestada los últimos años, por una parte, por líderes y partidos de derecha reacios a la globalización; y por otra, por movimientos sociales y partidos-movimiento, principalmente en aquellos lugares donde la crisis económica afectó de manera considerable, como fue el caso de España y Grecia. A esta contestación política y el consecuente aumento de antagonismo es lo que Mouffe denomina el "Momento Populista". Vale decir, sería éste el momento en el que se estaría conformando una frontera antagónica mediante una estrategia discursiva en la que se divide el pueblo de los que tienen el poder producto de heterogéneas y numerosas demandas (ambientales, minorías sexuales, étnicas) que no han sido satisfechas por la institucionalidad imperante. Entonces, siguiendo a Laclau (2005), la autora entiende por populismo una estrategia discursiva que construye una frontera política que divide a un nosotros de un ellos, calificándolo además, como un discurso que no tiene una ideología en particular, un contenido (programa) específico, ni tampoco es un régimen político.

Así, entonces, en términos gramscianos, Mouffe reconoce en la actualidad un interregno, esto es, un período en el que el proyecto hegemónico neoliberal está siendo desafiado por distintos grupos que están resistiendo las transformaciones que sacudieron a Europa desde fines de 1970 y que han socavado profundamente al Estado Bienestar. Sin embargo, advierte la autora, los primeros grupos que se opusieron no fueron grupos provenientes de la izquierda (devenida en tercera vía), sino de derecha. Y he aquí un hallazgo fundamental, pues lo que está sosteniendo Mouffe es que la resistencia no solo se ha producido por razones económicas, sino que fundamentalmente por la necesidad de mayor democracia, entendida como reivindicación de la soberanía popular. En este sentido, el momento populista, pues, no es otro que la vuelta de la política después de años de postpolítica y la afirmación de una consciencia democrática que se desliga de todas aquellas corrientes que ven lo político tan solo como un agregado institucional. Así las cosas, Mouffe propone sin atisbo de duda que la política del futuro será de tipo populista y no habrá otra alternativa que optar entre un populismo de derecha de otro de izquierda. Arguye la autora, que ambos se diferenciarían por la composición del nosotros y cómo se define al adversario. Mientras el populismo de derecha entiende el nosotros desde una soberanía nacional ajena de los dictados de organismos internacionales y excluye a todos aquellos que no son los "verdaderos" nacionales, el populismo de izquierda, en cambio, apuesta a recuperar la democracia y extenderla, incluyendo en este proceso a inmigrantes, trabajadores y a la clase media en una cadena de equivalentes en contra de los de arriba. Pero también se diferenciarían porque solo el populismo de izquierda permitiría radicalizar la democracia. ¿Cómo?. Mediante la presencia de un líder que institucionalice las distintas demandas de inclusión, soberanía popular e igualdad no en términos esencialistas de clase, sino en torno a demandas que incluso muchas veces no tienen que ver con un cambio radical del modelo capitalista. En este punto, por cierto, se revela ante el lector el proyecto político de Mouffe: ello, porque la autora dirige sus dardos en contra de la izquierda revolucionaria, que esencializa la clase y que ve al Estado como un mecanismo de explotación burguesa, pero también contra aquella pseudo-izquierda que se hizo de centro y renunció a antagonizar el modelo 
neoliberal. Lo que propone Mouffe, entonces, es paradójicamente la continuación del proyecto socialista con una estrategia de tipo socialista. Si Hegemonía y Estrategia Socialista fue duramente rechazado por un gran número de autores en el pasado, quedará por ver cómo terminará siendo leída esta propuesta.

Quisiera por último detenerme en tres aspectos conceptuales que podrían complementar el debate a futuro:

En primer lugar, respecto al momento populista. Si bien Mouffe considera que se está ante una crisis hegemónica (5) a la usanza gramsciana, pareciera ser que, por una parte, sitúa y limita el momento populista solo a tiempos de postpolítica (pese a que reconoce en Tatcher una estrategia populista); y por otro, no identifica crisis hegemónica con momento populista. Por más que se acepte que se está en un período de inflexión democrática producto de la crisis neoliberal, el limitar el momento populista a tiempos actuales no permitiría dar cuenta de procesos populistas que se dieron en el pasado y que podrían darse en el futuro. Al mismo tiempo, no queda del todo claro el hecho que una construcción populista que provenga de la derecha, pueda no enfrentarse al neoliberalismo, pues ha sido éste, en palabras de la autora, el que propició la postpolítica. Vale decir, ¿cómo se puede generar una articulación democrática si no se combate precisamente lo que inhibe el proceso democrático?. Frente a estas problemáticas, considero que se debería apuntar, primero, a identificar momento populista con crisis hegemónica; segundo, no limitar dicho momento a un contexto ni espacio geográfico determinado; y tercero, asumir que no toda crisis hegemónica desembocará en un proceso populista, pues este puede derivar en una revolución, un aggiornamiento del régimen o un régimen autoritario (Riveros, 2018).

En segundo lugar, y siguiendo en esto a Laclau, Mouffe enfatiza el carácter ontológico de la construcción discursiva populista por sobre cualquier contenido que pudiese tener dicha articulación. De hecho, Mouffe no se equivoca al señalar que el populismo, como construcción discursiva, puede tener significados de derecha como de izquierda. Incluso va más allá en su argumentación, al afirmar que habría que reconocer en los discursos populistas de derecha una demanda democrática, pues "provienen de grupos que perdieron por la globalización neoliberal” (21). Por cierto que en un contexto de ausencia de lo político, toda articulación que demande la soberanía popular será vista como democrática, pero la autora no profundiza cómo demandas excluyentes, proneoliberales o que colinden con el filo-fascismo puedan ser democráticas. En estos aspectos, pareciera ser que Mouffe está planteando que ante la ausencia de antagonismo en la política, la población apoyará todos aquellos discursos que avalen una política agonista, sin importar tanto, al menos en una primera instancia, el contenido de dichas políticas, sin embargo, sería difícil distinguir en qué momento discursivo (anterior al régimen, o si se quiere, a su institucionalización) se adquiere una tonalidad de derecha o de izquierda.

En tercer lugar, no queda muy claro por qué Mouffe se resiste a catalogar el populismo como un régimen, pese a que exige una sinergia entre movilización e institucionalidad. Para la autora, la institucionalización del discurso populista en, para y por el Estado, es una condición esencial para su triunfo. Sugiere que es ahí donde el líder junto a los ciudadanos, constituirán un espacio de auténtica soberanía nacional en el que se podrán cumplir las decisiones tomadas por la comunidad. Puede no existir algo como un "programa" populista, pero sí se debería aceptar que la estrategia discursiva populista lleva consigo un proyecto normativo que intentará plasmar en un gobierno. Así entonces, se podría calificar, por ejemplo, a un gobierno como un régimen populista de corte socialista o de tipo autoritario. Con todo, lo que no podría existir es un régimen populista sin una articulación discursiva populista previa. Por último, la ventaja de reconocer la presencia de un régimen, permitiría determinar con mayor claridad si los discursos esgrimidos son de derecha o de izquierda.

Con todo, estas observaciones no hacen mella en este excelente ensayo, sobre todo, para un término que se ha convertido muchas veces en un insulto más que un adecuado objeto de análisis. A decir verdad, tanto la noción de "Momento Populista" como de institucionalización de éste constituyen aportes fundamentales para la profundización teórica preconizada por Laclau y que Mouffe continúa con luces propias.

\section{Bibliografía}

Laclau, Ernesto y Chantal Mouffe, Hegemonía y Estrategia Socialista. Buenos Aires: Fondo de Cultura Económica (2010). 
Laclau, Ernesto, La razón populista. Buenos Aires: Fondo de Cultura Económica (2005).

Mouffe, Chantal, On the Political. Abingdon: Routledge (2005).

Mouffe, Chantal, The Democratic Paradox. London: Verso (2000).

Riveros, Claudio, El proceso populista: momento, fenómeno, régimen. Raleigh, NC: A Contracorriente, UNC Press (2018). 